\title{
Effect of impeller blades on water resistance coefficient and efficiency of mixed-flow pump
}

\author{
Du Yuanying ${ }^{\mathrm{a}}$, Shang Changchun ${ }^{\mathrm{b}}$, Zhang Kepeng $^{\mathrm{c}}, \mathrm{Hao} \mathrm{Yuyu}^{\mathrm{d}}$ \\ and Wang Peng ${ }^{\mathrm{e}}$ \\ Engineering training Center, Xi'an University of Science and Technology, Xi'an, 710054, Shaanxi, \\ China. \\ a562295292@qq.com, b545834818@qq.com, ${ }^{\circ} 531756969 @ q q . c o m$.
}

Keywords: mixed-flow pump; water resistance coefficient; number of impeller blades; efficiency; numerical simulation.

\begin{abstract}
In order to investigate effects of impeller blades on performance in mixed -flow pump, using unstructured tetrahedral mesh and SIMPLE algorithm, the simulation of three-dimensional flow inside a mixed-flow pump were done in Fluent. Adopting the time-averaged continuity equation, N-S equation and RNG k- $\varepsilon$ turbulence model in a relative coordinate system. The static pressure and absolute velocity distributions of impeller blades and stator blades were simulated. Under different blades, the flow resistance coefficient across pump was estimated in static, performance parameter was estimated in dynamic condition. It's found that water resistance coefficient and head were gradually increased, and efficiency firstly increased and then decreased with unobvious trend while rest geometrical unchanged. The results showed that: under special environment, design condition, number of impeller blades should as small as possible to meet efficiency requirement under a particular application. In addition, the optimum performance was achieved at 4 blades and 3 guide vanes.
\end{abstract}

\section{Introduction}

Mixed flow pump is a basic type of vane pump, the scope of the specific speed is from 300 to 600 , which is easy to start and have high efficiency, it have broad prospect in cooling water circulation system of nuclear power plant, propulsion system, water cycle of power plant and water desalination devices.

Currently, Li Yibin etc have studied performance of internal flow field in mixed-flow pump ${ }^{[1]}$, the results have guiding significance for design efficient and running stable pump. Some researchers have studied effect of parameters of mixed-flow pump ${ }^{[2-3]}$, Yang Congxin etc have studied the distance between impeller and guide vane in mixed-flow pump ${ }^{[4]}$. But materials about effects of impeller blades on water resistance coefficient and efficiency in mixed-flow pump were less.

In this paper, under design conditions, specific speed is 504, through simulation of the three-dimensional flow inside mixed-flow pump by Fluent, trying to find some rules of water resistance coefficient and performance of mixed flow pump.

\section{The basic theory}

\subsection{Calculation model}

Assumed fluid is incompressible, stationary, excluding influence of gravity, Chose Reynolds-average equations as control equations ${ }^{[5]}$. It's form as follow: 


$$
\left\{\begin{array}{l}
\rho u_{x}+\rho v_{y}+\rho \omega_{z}=0 \\
(\rho u u)_{x}+(\rho v u)_{y}+(\rho \omega u)_{z}-\left(\mu_{\mathrm{e}} u_{x}\right) \\
-\left(\mu_{\mathrm{e}} u_{y}\right)_{y}-\left(\mu_{\mathrm{e}} u_{z}\right)_{z}=S_{u}-p_{x}-F_{\mathrm{cx}} \\
(\rho u v)_{x}+(\rho v)_{y}+(\rho \omega v)_{z}-\left(\mu_{\mathrm{e}} v_{x}\right)_{x} \\
-\left(\mu_{\mathrm{e}} v_{y}\right)_{y}-\left(\mu_{\mathrm{e}} v_{z}\right)_{z}=S_{v}-p_{y}-F_{\mathrm{cy}} \\
(\rho u \omega)_{x}+(\rho v \omega)_{y}+(\rho \omega \omega)_{z}-\left(\mu_{\mathrm{e}} \omega_{x}\right)_{x} \\
-\left(\mu_{\mathrm{e}} \omega_{y}\right)_{y}-\left(\mu_{\mathrm{e}} \omega_{z}\right)_{z}=S_{\omega}-p_{z}
\end{array}\right.
$$

In the equation: $p_{x}=\frac{\partial p}{\partial x}-\omega^{2} x, p_{y}=\frac{\partial p}{\partial y}-\omega^{2} y, p_{z}=\frac{\partial p}{\partial z} ; \quad F_{c x}=-2 v \omega, F_{c y}=2 u \omega$.

$R N G k-\varepsilon$ model considering precision of large curvature, it's more suitable for calculation of flow field in the hydraulic machinery ${ }^{[5]}$.

$$
\frac{\partial v_{i} k}{\partial x_{i}}=\frac{\partial}{\partial x_{i}}\left[\left(v+\frac{v_{\mathrm{t}}}{\sigma_{k}}\right)\left(\frac{\partial k}{\partial x_{i}}\right)\right]+p_{\mathrm{r}}-\varepsilon \quad \frac{\partial v_{i} \varepsilon}{\partial x_{i}}=\frac{\partial}{\partial x_{i}}\left[\left(v+\frac{v_{\mathrm{t}}}{\sigma_{\varepsilon}}\right)\left(\frac{\partial \varepsilon}{\partial x_{i}}\right)\right]+\frac{C_{\varepsilon 1} \varepsilon p_{\mathrm{r}}-C_{\varepsilon 2} \varepsilon^{2}}{k}
$$

In the equation: $p_{r}=v_{\mathrm{t}}\left(\frac{\partial v_{i}}{\partial x_{i}}+\frac{\partial v_{j}}{\partial x_{i}}\right) \frac{\partial v_{i}}{\partial x_{j}}, \quad v_{\mathrm{t}}=C_{\mu} \frac{k^{2}}{\varepsilon}, \eta=\frac{S k}{\varepsilon}, \quad C_{\mu}=0.0845 ; \quad S=\sqrt{2 \bar{S}_{i, j} \bar{S}_{i, j}}$, $\bar{S}_{i, j}=\frac{1}{2}\left(\frac{\partial V_{i}}{\partial x_{j}}+\frac{\partial V_{j}}{\partial x_{i}}\right) ; \beta=0.012 ; C_{\varepsilon 2}=1.68 ; C_{z}=0.7179 ; \sigma_{k}=0.7179$.

\subsection{Boundary conditions}

(1) Inlet and outlet conditions: used incompressible water as medium, inlet was velocity-inlet, turbulent flow was full-blown, outlet was outflow ${ }^{[5]}$.

(2) Solid wall conditions: impeller was rotating wall and no-slip mesh, inlet pipe, guide blade and outlet pipe all used static wall and no slip mesh.

\subsection{Performance prediction model}

Head and efficiency of pump's prediction formula are as follow. In the equation: $\Delta Z$ stands for vertical distance between outlet and inlet of pump, $\mathrm{P}_{\text {out }}, \mathrm{P}_{\text {in }}$ stand for average pressure of pump at inlet and outlet, $\mathrm{H}_{\mathrm{d}}$ for design condition head.

$$
\begin{array}{r}
H=\frac{P_{\text {out }}}{\rho g}-\frac{P_{\text {in }}}{\rho g}+\Delta z \\
\phi=H / H_{d} \\
\eta=\frac{\rho g Q H}{P}
\end{array}
$$

\subsection{The formula of static water resistance coefficient}

Water resistance coefficient $\mathrm{k}$ is positive, when pump is static and fluid flow from guide vane and diffuser. Resistance coefficient $\mathrm{k}$ is defined as follows:

$$
\mathrm{k}=2 \mathrm{~g} \Delta \mathrm{h} / \mathrm{v} 2
$$

In the equation: $\Delta \mathrm{h}$ stands for hydraulic loss of pump at inlet and outlet, $\mathrm{v}$ stand for cross-section velocity of reference.

\section{The description of model and numerical method}

\section{1 key parameter}

The flow rate of mixed flow pump $Q=1400 \mathrm{~m}^{3} / \mathrm{s}$, rotational speed $\mathrm{n}=2900 \mathrm{r} / \mathrm{min}$, impeller diameter $\mathrm{D}=240 \mathrm{~mm}$, outlet width of impeller $\mathrm{b}=76 \mathrm{~mm}$, blade number of impeller $\mathrm{Zg}=4$, guide vane number $\mathrm{Z}=3$, length-width ratio of guide vane $\lambda=0.3$.

\subsection{Solid Meshing Methods}

Overflow of pump included inlet pipe, impeller, guide vane and diffusion tube. The grid meshed by Gambit. In order to improve calculation accuracy, computational domain used grid refinement method, ensuring calculation result did not depend on grid number, the minimum number of grid was determined about 1276948. The calculation model is shown in figure 1. 


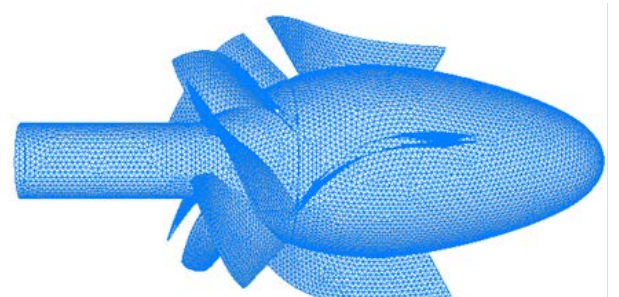

\subsection{Numerical computation method}

Fig.1 Calculation model of mixed-flow pump

Finite volume method was used to discrete control equations, in order to strengthen convergence of calculation, discretion and convective term adopted first order upwind. The couple of pressure and velocity used SIMPLEC algorithm.

\section{Results and analysis}

\subsection{The results and analysis of numerical calculation}

The static pressure distribution of mixed flow pump blades and guide vane were simulated by FLUENT, it is shown in figure 2.
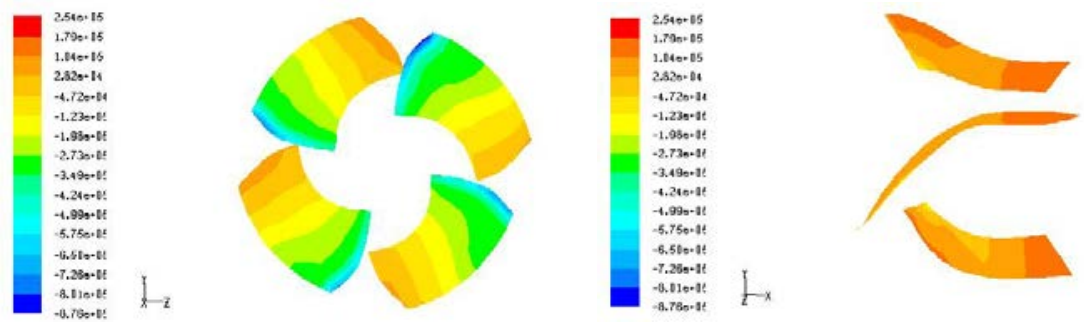

Fig.2 Static pressure distribution under design condition.(unit: $\mathrm{Pa}$ )

It can be seen from Fig. 2 that: liquid obtain energy from rotation impeller, static pressure distribution of suction surface at impeller blade increased gradually and reached maximum at the tip of blade, there was obvious zone of negative pressure at inlet of suction surface, this position is easy to appear cavitation, Guide vane made flow smooth, which translated kinetic energy into pressure energy, pressure reached maximum in the middle of guide vane ,but it reduced at outlet of guide vane, overall flow condition was smooth and in accordance with the actual situation.

Absolute velocity distribution under design condition is shown in figure 3.

It can be seen from Fig. 3 that: from inlet to outlet of blade, the absolute velocity distribution increased gradually with blade height direction, overall flow was smooth, and did not exist lateral flow and flow separation. Streamline of liquid which was flow from outlet of impeller was smooth, The velocity was gradually decrease, in which kinetic energy was translated into pressure energy, flow trend from inlet to outlet of guide vane was smooth.
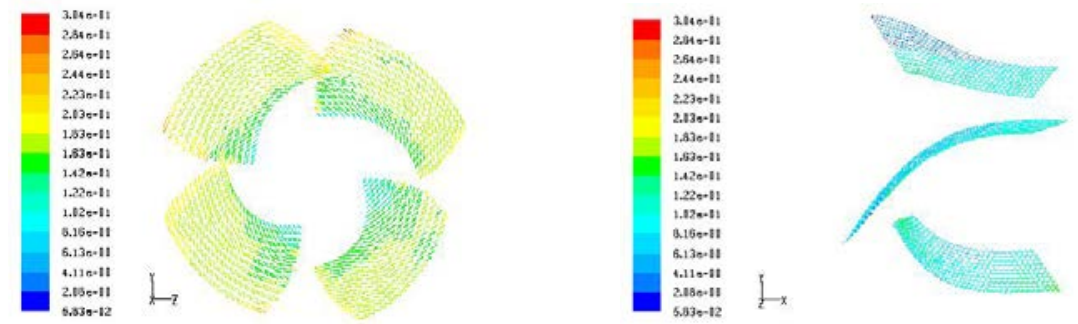

Fig.3 Absolute velocity distribution under design condition (unit: $\mathrm{m} / \mathrm{s}$ )

\subsection{The prediction and analysis of performance}

Impeller is vital part of pump, The blade numbers have significant influence on head, efficiency and resistance. In generally, the impact was non-linear, but from the point of optimal performance, mixed flow-pump must have optimal blade number.

\subsubsection{The influence of impeller blades number on water resistance coefficient.}

When impeller static, under design conditions, guide vane number was 3 , outlet angle of guide blade was $90^{\circ}$, within limited space, other parameters were constant, the number of blades (Zg) 
were 4,6,8, mixed flow pump was simulated, the formula (6) was used and water resistance coefficient was calculated as shown in table 1.

Table 1 water resistance coefficient under different impeller blade number

\begin{tabular}{cc}
\hline Number of impeller blades & Water resistance coefficient \\
\hline 4 & 28.85 \\
6 & 29.06 \\
8 & 31.08
\end{tabular}

It can be seen from table 1: Resistance coefficient was lowest at 4 impeller blades and 3 guide blades, water resistance coefficient was gradually increased with number from 4 to 8 of impeller blades.

There are mainly two reasons: (1) with increase of impeller blade numbers, expulsion of blades were gradually increased, tangent surface area was increased, so friction of blade surface was increased, the motivate particle has to overcome increased resistance, so energy loss and water resistance coefficient were increased.

(2) the distance between impeller blades was decreased, binding effect of impeller blades was increased, destabilization by impeller blades of fluid particle which flow nearby impeller was increased, which made them deviate from original path, the mechanical energy which was overcome exchange momentum was increased, the energy loss and water resistance coefficient were increased.

\subsubsection{The effects on head and efficiency of number of impeller blades.}

When the impeller rotated, under design conditions, mixed flow pump was simulated when impeller blades were 4, 6, 8, formula (3), (4), (5) were used to simulate head and efficiency, curves of head and efficiency VS number of stator blades were plotted. It's shown in figure 4.

It can be seen from the figure4: with number of impeller blades increased, head showed a trend of increasing, efficiency firstly increased and then decreased with unobvious trend.

There are mainly two reasons: (1) With the increasing of blade number, the restriction of liquid by blades was increased, the sliding coefficient increased, while loss of separation and spread of impeller blade were reduced, so head was increased. (2) Blades transmitted torque to liquid, increased surface of blades made liquid flow more smooth, and loss of separation and diffusion were weak, so head was increased.

The reason of efficiency firstly increased was that: due to eddy motion, slip phenomenon, loss of separation were weaken, efficiency was increased; the reason of efficiency decreased was that: due to expulsion was increased, friction of blade surface was increased, mechanical energy which was overcame resistance was increased, so efficiency was declined.

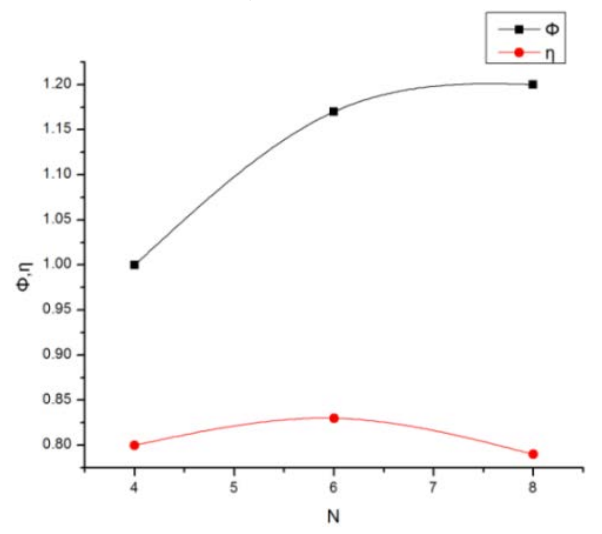

Fig.4 Curves of head and efficiency VS impeller blades number

\section{Summary}

(1) Under special environment, in order to ensure whole system have well circulation and stable system, which required low water resistance coefficient. So the number of blades should as less as possible in the premise of efficient. 
(2) It's found that the optimum performance of mixed flow pump was achieved at 4 blades and 3 guide vanes, at which could obtain requirement and have the lowest water resistance in static and highest efficiency in dynamic, that have some references for design similar type pump.

\section{References}

[1] Li Yibin,Li Rennian,Wang Xiuyong,Han Wei,Gao Qiang. Numerical analysis of pressure fluctuation in low specific speed mixed-flow pump [J]. Journal of Drainage and Irrigation Machinery Engineering, 2013,31(3):205-209

[2] Felix A.Muggli Peter Holbein. CFD calculation of a mixed flow pump characteristic from shutoff to maximum flow[J] .ASME, 2002:799-802

[3] Liu Zhenyi,Huang Xiaojun,Cheng Kuangmin. The analysis and calculation of hydraulic friction resistance in the impeller of mixed flow pump [J]. fluid machinery ,1995, 10(4):21-25

[4] Yang Congxin,Du Yuanying, Li Yibin. Effects of guide vanes parameters on water resistance coefficient and efficiency of mixed-flow pump[J]. Journal of Drainage and Irrigation Machinery Engineering, 20012:9(35):538-542.

[5] Wang Fujun. The dynamics analysis of computational fluid, principle and application of CFD software [M].Beijing: Tsinghua University Press,2004. 